MedieKultur | Journal of media and communication research | ISSN 1901-9726

Introduction

\title{
Researching users across media
}

\section{Anne Mette Thorhauge, Kjetil Sandvik \& Tem Frank Andersen}

MedieKultur 2016, 60, 1-5

\begin{abstract}
Published by SMID | Society of Media researchers In Denmark | www.smid.dk The online version of this text can be found open access at www.mediekultur.dk
\end{abstract}

The emergence of the Internet and digital technologies has brought about a massive proliferation of communication services and platforms since the mid-1990s (Helles, 2013), turning communication across media into a key perspective in media research. Much of this research has had its focus on media institutions and their communication strategies (Davidson, 2010; Erdal, 2009) and media environments (Madianou \& Miller, 2012), whereas cross-media communication as a user strategy has received relatively less attention. For this reason, the focus of this issue of MedieKultur will be on the user perspective proper and will pose the question: What are the methodological frameworks needed to study users across media?

An important aspect for understanding the user perspective today is to consider the diverse modes of engagement and various degrees of participation with which media content is shared, distributed, commented on, edited and added to and how they greatly expand the range of activities that may be included in the concept of "media use". Another key aspect is the growing complexity of use contexts that cut across diverse locations and blur the boundaries between online and offline contexts, making it increasingly difficult to delimit in a clear manner what should be included and what should be excluded as an aspect of the context of use. Finally, the mobility and individualisation of digital communication technologies have greatly expanded their integration into various aspects of everyday life, including dating, maintaining friendships and going to work. They have, therefore, 
greatly expanded the range of everyday practices of which media use and cross-media communication may be a part.

Apart from changing the way we use and combine media as a part of ordinary and extraordinary situations in our everyday lives, this also poses challenges to the way we study users empirically across media. The use of particular media platforms cannot be fully understood without grasping the broader media environment of which they are part and the physical contexts and everyday practices to which media use can be related are distributed in time and space, making it difficult to demarcate and frame them as phenomena that can be studied empirically. Hence, the key focus of this theme issue is how methodologically to approach user communication across media. The individual articles have taken up this challenge from a range of perspectives that include different empirical domains (such as dating, travelling and searching for news), different analytical frameworks (such as media repertoires, online ethnography and the "experience economy") and different empirical approaches (such as network analysis, interviews, observations and log data analysis). In "From everyday communicative figurations to rigorous audience news repertoires", Kim Schrøder and Christian Kobbernagel suggest a mixed-methods approach that includes Q-methodology, card sorting and qualitative interviews to identify and describe patterns of news consumption among participants across platforms and services. The article demonstrates how this interpretive, factor-analytical procedure, which results in the building of six audience news-repertoires in Denmark, also preserves the qualitative thickness of the participants' verbal accounts of the communicative figurations of their everyday life with the news media. In "The media go-along: Researching mobilities with media at hand", Kristian Møller Jørgensen combines observations and interviews with verbal and visual "tours" of participants' personal dating sites as a way of understanding their media practices and experiences. The article demonstrates how mobile media analysis, based on the media go-along's representations of verbal, material, affective, and kinetic aspects of social interaction, is useful in an analysis of the socially-conditioned access to and production of single media practice and experience. In "Researching intimacy through social media: A cross-platform approach", Christina Miguel guides us through the process of recruiting and tracking participants as they form and maintain relationships across various social platforms. The article argues that a cross-platform approach and a multi-method research design are helpful to investigate the nature of intimacy practices facilitated by social media since these practices are conducted online/offline, across different platforms, among different types of relationships, within both new and existing relationships, and in different locations. In "Cross-media communication in context: A multi-method approach", Anne Mette Thorhauge and Stine Lomborg demonstrate how the combined analysis of smartphone use data and users' own qualitative accounts provides new insights into the everyday contexts and practices of cross-media communication. As such, the article complements prior studies on smartphone use, approaching the topic primarily from a quantitative point of view that focuses on automatically logged use data as an alternative, for instance, to survey 
data. In "Investigating communication networks contextually: Qualitative network analysis as cross-media research", Andreas Hepp, Cindy Roitsch and Mathias Berg introduce the approach of contextualised communication network analysis as a qualitative procedure for researching communicative relationships realised through the media. The article demonstrates how a combination of qualitative interviews on media appropriation, egocentric network maps, and media diaries enables a differentiated insight into the specific meanings, structures and processes of communication networks across a variety of media. In "Transmedial analysis in a networked world: An experience-centred approach", Lisbeth Klastrup and Susana Tosca argue that mapping user experience requires a sophisticated and holistic analytical approach - in particular, due to the popularity of social media platforms. The authors conclude the article by developing the concept of "networked reception" to characterise the new kinds of transmedial world experience afforded by social media, which allow users to distribute and communicate not only the content of media texts but also their own experience and reception of the transmedial world "texts".

Together, this collection of articles outlines the vast range of analytical frameworks, empirical domains and methodological considerations that are put into play when crossmedia communication is approached from a user perspective and sketches out some relevant directions for future research. A recurring theme is the combination of several methods and data types, including qualitative and quantitative data, in the attempt to pinpoint and contextualise cross-media uses from a user perspective. Another recurring theme is the innovative application of traditional methodological approaches such as Q-methodology and media go-alongs as a way of getting closer to the user's perspective on cross-media communication. Finally, some of the articles emphasise the inclusion of somewhat new types of data such as network data and manually logged use data as alternative ways to map use patterns across media. Although each article represents a substantial contribution within its own field, these general themes point out relevant directions for future research as well.

This issue's Open Section consists of four articles (two in English, two in Danish). In "Colonising the academy? Organisational mediatisation and public research institutions in Norway", Torgeir Uberg Nærland focuses on the impact of journalistic news media and argues that public research institutions are increasingly adapting to their media environments in terms of both organisational structure and communication practice even though they are less able to internalise news media logic to such an extent that it critically impinges on processes and prioritisations in key operational areas such as research dissemination, the execution of research projects and managerial decision-making. In "Fra monteret monolog til direkte dialog" ["From monologue montage to direct dialogue"], Freja Sørine Adler Berg investigates the development of program formats in public service talk radio from the closure of the documentary department at DR (Danish Broadcasting Corporation) in 2007 to the arrival of the public service radio station Radio 24/7, established in 2011 to replenish the overall supply of radio programming. The article studies the significant drop 
in reading, reporting, location broadcasting, and edited artistic genres, such as radio drama and documentary, and argues that the increase of studio programs reflects the prioritisation by public service institutions of journalistic content over exploring the medium's aural possibilities. It also reflects the diminished importance of creating programmes with high production value. In "En systematik for idéudviklingsformater" ["A systematic approach to idea development formats"], Brian Due focuses on the lack of accurate knowledge within media and communication studies when it comes to how ideas are developed in authentic social interaction. Through a series of examples, the article demonstrates which communicative formats participants use when they propose ideas and how ideas are accepted or critiqued. The article presents a number of formats that have been analysed with video ethnographic and conversation analytical methods in order to provide an overview of the most common communicative formats during idea generation sessions. In "Feed the dogs: A case of humanitarian communication in social media", Gry Høngsmark Knudsen and Domen Bajde address negative aspects of the interplay between networked media and humanitarian communication through the lens of mediatization theory. Using mediatization theory, the authors identify aspects of social media processes that challenge the current practice of humanitarian communication and suggest that broadening the consideration of media amalgamation enables a critical discussion of humanitarianism in networked media.

\section{References}

Davidson, D. (2010). Cross-Media Communications: An Introduction to the Art of Creating Integrated Media Experiences. ETC Press.

Erdal, I.J. (2009). Cross-media (re) production cultures. Convergence: The International Journal of Research into New Media Technologies, 15(2), 215-231.

Helles, R. (2013). Mobile communication and intermediality. Mobile Media \& Communication, 1(1), 14-19.

Madianou, M., \& Miller, D. (2012). Polymedia: Towards a new theory of digital media in interpersonal communication. International Journal of Cultural Studies. doi:10.1177/1367877912452486

Anne Mette Thorhauge, PhD

Associate professor

Department of Media, Cognition and Communication

University of Copenhagen, Denmark

annemette@thorhauge.dk 
Introduction: Researching users across media

Kjetil Sandvik, PhD

Associate professor

Department of Media, Cognition and Communication

University of Copenhagen Denmark

Sandvik@hum.ku.dk

Tem Frank Andersen, PhD

Associate professor

Department of Communication and Psychology,

Aalborg university, Denmark

tfa@hum.aau.dk 